\title{
A stable, oligosymptomatic malaria focus in Thailand
}

\author{
Ronald Rosenberg ${ }^{1}$, Richard G. Andre ${ }^{1}$, Songkram Ngampatom ${ }^{2}$, Christoph Hatz $^{3}$ and Robert \\ Burge ${ }^{4}$ 'Department of Entomology, Armed Forces Research Institute of Medical Sciences, Bangkok, Thailand; \\ ${ }^{2}$ Malaria Division, Ministry of Public Health, Bangkok, Thailand; ${ }^{3}$ Swiss Tropical Institute, Basle, Switzerland; \\ ${ }^{4}$ Department of Biometrics, Walter Reed Army Institute of Research, Washington, DC, USA
}

\begin{abstract}
Blood from most of the 250 residents of a nonmigratory farming village in south-eastern Thailand was visually examined for malaria parasites monthly for 2 years. Nearly $97 \%$ of the population had at least one (median=5) patent Plasmodium falciparum infection per year; $72 \%$ had one due to $P$. vivax (median $=1$ ). This contrasted with a slide positivity rate of $17 \%$ calculated from 12 months of passive case detection before the study began. Children 1-9 years old had the highest mean monthly prevalence $(51 \%)$ and highest geometric mean density (10/500 white blood cells) of $P$. falciparum. Fewer than half the expected number of mixed infections were found but these were more common at high densities of $P$. falciparum. Individuals over 19 years old comprised $52 \%$ of the population but accounted for only $18 \%$ of $P$. vivax and $32 \%$ of $P$. falciparum gametocytaemias. Fever rates were marginally higher in those below 10 years old $(8 \%)$ but occurred with equal frequency in those with patent infections or negative. The spleen rate $89 \%$ stage 1 ) was $24 \%$ in those under 15 years old and $7 \%$ in those older. No malaria mortality was seen. $P$. falciparum cases treated for $10 \mathrm{~d}$ with quinine+tetracycline (QT) cleared the infection as often as those given one dose of mefloquine + sulfadoxine + pyrimethamine (MSP); both treatments reduced densities in cases not cured. Apparently unsupervised compliance was no better with MSP than with QT. The role played by hyperendemic, cryptic foci in Asian epidemics of malaria may have been underestimated.
\end{abstract}

\section{Introduction}

Malaria suppression campaigns often leave behind small, persistent foci of transmission which may initiate catastrophic epidemics in neighbouring, nonimmune populations. A common epidemic agent is human migration; emigrants from an endemic focus may, for instance, introduce the parasite into an area with no transmission but capable vectors. More explosive, however, because gradual acceleration of the epidemic reproduction rate is circumvented (MACDONALD, 1957), are outbreaks in non-immune groups that have moved into endemic areas to live or work, an increasingly common occurrence in countries where natural resources are dwindling (KONDRASHIN \& ORLOV, 1985). In either case, a consequence of prolonged migration of infected persons may be the wide geographical dissemination of drug-resistant strains (CLYDE, 1987).

Correspondence: AFRIMS, APO San Francisco, CA 96346, USA.
In Thailand epidemic surveillance is maintained by a vast and efficient network of professional and volunteer malaria workers who use as their principal tool passive case detection (PCD) (MALARIA DIVISION, 1982). In PCD, records are compiled of those people who, having felt ill with symptoms of what could be malaria, present themselves to a government malaria worker or to a clinic. Since epidemics take place among non-immunes, and non-immunes infected with malaria almost always become seriously ill, this is a sensitive and economical means of detecting incipient outbreaks among the 10.5 million people living in areas of risk. PCD does not, however, accurately portray hyperendemic foci, where transmission is intense but the semi-immune inhabitants seldom display symptoms; as a result, reliance on PCD may underestimate national prevalence and overlook the precise sources of epidemics (BLACK, 1968). Reports of malaria outbreaks in eastern Thailand, for instance, have usually disregarded the epidemic source or have assumed some vague origin in the forest, despite lack of evidence of how a forest cycle was maintained (MALARIA DIVISION, 1982).

In this report we describe a prosperous farming community in a well-developed section of southeastern Thailand that displays few signs of malaria but which is, in fact, hyperendemic. During 24 consecutive months we compared how well different surveillance methods depicted prevalence in this village and the relative efficacy of quinine+tetracycline (QT) or mefloquine + sulfadoxine + pyrimethamine (MSP) treatment in reducing cases of Plasmodium falciparum infection. We used our findings to evaluate the meaning of the recent, apparent drop in number of cases in Thailand and to suggest modifications to current surveillance strategy. In subsequent papers we shall detail the dynamics of malaria transmission in this same community.

\section{Area}

Ban Phluang (village 7, Makaam Amphoe, Chantaburi Province), in the south-eastern sector of Thailand $\left(12^{\circ} 48^{\prime} \mathrm{N}, 102^{\circ} 09^{\prime} \mathrm{E}\right)$, is a region of broad valleys and of hills ranging from 100 to $1000 \mathrm{~m}$ high. Except for a large forest preserve several kilometers to the north of the village, virtually all the area has long been cleared of native forest and replanted with rubber, rambutan, durian, mangosteen, and other tree crops interspersed with rice. The $\mathbf{4 8}$ houses at the study site constituted the eastern half of the village and were strung along a valley floor drained by a large, meandering, perennial stream fed by numerous tributaries. Orchard crops brought high prices and the village was relatively prosperous: many families had 
wells, concrete latrines, and bicycles; some owned television sets or trucks. Residents seldom worked away from the village; they themselves sometimes hired workers from other eastern districts to help with the summer fruit harvest. Every January and February hundreds of outsiders spent one or more nights in the village before making a pilgrimage to Buddhist holy places in the hills above the village.

The nearest government malaria outpost was the malaria sector office, staffed by several technicians, about $6 \mathrm{~km}$ away on an all-weather road. The primary means of surveillance was by $\mathrm{PCD}$; usually, no more than $60 \mathrm{~min}$ elapsed from time of arrival at the sector office until treatment, if required. All slides were re-examined weekly at the zone office, the next higher administrative level, in Chantaburi city. Several times a year malaria workers held a one-evening clinic in the village and solicited blood films from people who had recently felt ill (active case detection or ACD), or conducted mass surveys, usually in the schools. Combined PCD and ACD records for the 12 months of 1982 accounted for 145 blood films from village 7 , which included the study site, $16 \cdot 6 \%$ of which were positive; as about 1000 people occupy village 7 , this gives an annual parasite index of $24 \cdot 1$. Twice yearly, in March and August, house interiors were sprayed with fenitrothion at $1 \mathrm{~g} / \mathrm{m}^{2}$ or DDT at $2 \mathrm{~g} / \mathrm{m}^{2}$.

\section{Methods}

The research team stayed at the study site for 8-15 d each month for 24 consecutive months. The first year of the study was from June 1983 to May 1984; the second year was from June 1984 to May 1985 .

\section{Blood collection and examination}

Numbered thick and thin films were made monthly from each resident and Giemsa-stained (BRUCECHWATT, 1961). Slides were examined within $72 \mathrm{~h}$ by several microscopists at the malaria zone office. Subsequently all slides were re-examined by a single microscopist, unaware of the previous results, in Bangkok; about $3 \%$, chosen at random, were examined a third time by one of the investigators or another technician. The zone microscopists used a standard procedure to examine the slides (BRUCECHWATT, 1961): 3-5 min were spent on each thick film (700 $\times$ oil immersion) before declaring it negative; when parasites were found, the number occuring in the presence of 100 white blood cells (WBC) were counted. Zone microscopists counted 1737 WBC (geometric mean, $n=50$ ) during a routine negative examination, compared to 1670 WBC per examination reported for 100 fields in another study (DowLING \& SHUTE, 1966). The re-checking microscopist used a fixed stopping point: thick films were examined at $1000 \times$ (oil immersion) until 500 WBC had been seen (about 10-15 min per slide), and all parasites seen in that volume were recorded. All densities reported in this paper were calculated from the re-check examination. We had earlier determined (from 336 films) that 500 WBC were equivalent to 232 fields of a grid reticule, $0.006 \mathrm{~mm}^{2}$, at $1000 \times$; using the method of EARLE \& PEREZ (1932), we calculate the mean WBC count for February 1985 $(n=165)$ to be $5500 / \mathrm{mm}^{3}$.

\section{Treatment}

Only those found positive during the initial slide examinations were treated; a malaria division employee distributed drugs within $4 \mathrm{~d}$ of specimen collection. Although investigators routinely confirmed that treatment had been delivered, they did not witness drugs being taken. Chloroquine, sulfadoxine-pyrimethamine, and antibiotics are easily available in Thailand (although not at Ban Phluang) and the possibility of occasional self-treatment cannot be excluded.

The study incorporated changes in the treatment of $P$. falciparum malaria made by the government of Thailand in 1984. During the first year adults positive for $P$. falciparum sexual or asexual forms were given oral quinine sulphate $(600 \mathrm{mg} \times 3 \times 3 \mathrm{~d})$, tetracycline hydrochloride ( $500 \mathrm{mg} \times 3 \times 7 \mathrm{~d}$ ), and a single $30 \mathrm{mg}$ (15 $\mathrm{mg} \times 2$ ) dose of primaquine, all begun on the same day (MALARIA DrvisION, 1982). In the second year adult cases were treated with a single dose of 3 tablets containing $750 \mathrm{mg}$ mefloquine, $1.5 \mathrm{~g}$ sulfadoxine, and $75 \mathrm{mg}$ pyrimethamine (MSP) as well as primaquine ( $2 \times 15 \mathrm{mg}$ ) (MFEK et al., 1986). MSP was from recently manufactured (Hoffman-Roche) Thai government stock. In both years the treatment for $P$. vivax was $1.5 \mathrm{~g}$ chloroquine base $(3 \mathrm{~d})$ and primaquine (15 mg $\times 14 \mathrm{~d}$ ) (MALARIA DivisION, 1982). Children received proportionately smaller doses according to an age scale issued by the government.

\section{Analysis of P. falciparum treatment data}

All age groups and both sexes were included and the presence of gametocytes discounted. Response to quinine+tetracycline (QT) was analysed for June 1983-January 1984 and that to MSP for June 1984 January 1985. Each period was divided into 7 overlapping pairs of months: June-July, July-August, August-September, etc. Individuals positive in the first month of any couplet were put into one of 4 categories determined by the results of the blood examination at the second month: (i) treated the first month, still parasitaemic in the second; (ii) treated, then negative; (iii) untreated, still parasitaemic; and (iv) untreated, then negative. Categories (iii) and (iv) included people whose parasitaemias were overlooked during the initial check, on which treatment was based.

\section{Spleen and temperature measurement}

In 4 months (November and December 1984 and February and June 1985) spleens were palpated in supine subjects by one of the investigators, a physician, and recorded using the standards suggested by HACKETT (1944). In 2 months an attempt was made to measure the oral or axillary temperature of all subjects less than 15 years old regardless of whether they complained of symptoms.

\section{Results}

The study population fluctuated between 243 and 256; data have been analysed from only those residents (excepting infants) who donated at least 8 specimens in a year, approximately $72 \%$ of the population, a total of 3772 films. Nearly all villagers had at least one patent episode of $P$. falciparum each year (Table 1), with $82 \%$ of those positive between 3 and 6 times annually (Fig. 1); P. vivax was found less 
frequently. Mixed infections were $<50 \%$ of the number expected, regardless of whether comparison was made by year, age, or season (Table 2). Only 1 subject, a 14 year old female, was not infected with either species during the entire 24 months. Both sexes had equal parasite rates in all age groups. Mean monthly prevalence for $P$. falciparum trophozoites was relatively consistent $(38 \pm 7.8 \%)$ and appeared to be independent of changes in season or treatment; $P$. vivax was erratic, ranging between $5 \%$ and $25 \%$. The occurrence of $P$. falciparum gametocytes, high trophozoite densities and prevalence in children did show marked seasonal fluctuations which are discussed elsewhere (ROSENBERG et al., 1990b).

Children aged 1-10 years were most frequently parasitized (Table 3). A significant drop in $P$. falciparum prevalence occurred between age groups 5-9 and 10-14 years; declines in prevalence of $P$. falciparum gametocytes and both forms of $P$. vivax were more gradual, but in all cases those $>14$ years old had significantly lower rates than did those aged 5-9 years (Fig. 2). The percentage of adults harbouring sexual forms of $P$. vivax was so small that they may not have contributed significantly to its transmission (Table 3).

Parasite levels were low: $54 \%$ of $P$. falciparum and $48 \%$ of $P$. vivax trophozoite infections were discovered at densities of $1-3 / 500$ WBC. The second screening of specimens uncovered 2.8 times more positives than did the first; nearly all those initially missed had the lower parasitaemias (Fig. 3). Virtually all positive cases and identifications found at the first check were reconfirmed. Among the 89 mixed infections, the frequency distribution of $P$. vivax densities $(52 \cdot 8 \% \leqslant 3 / 500$ WBC) was the same as for single infections, but $P$. falciparum densities $(22 \cdot 3 \% \leqslant 3 /$ 500 WBC) were higher.

Densities were highest in children; notably, $P$. falciparum gametocyte density fell sharply in the 5-9 years old cohort, after which it remained constant (Fig. 4). The strong positive correlation between age-group prevalence and age-group density in $P$. falciparum infections suggested that individuals most frequently infected would have the highest densities. A positive correlation was found (Fig. 5), relatively strongest in $1-4$ year olds $(r=0.405, t$ ratio $=1.66)$.

Mean haematocrit was $35 \cdot 2$ for children $<10$ years old, the same as that found in non-malarious rural regions of Thailand (HATHIRAT et al., 1976). Our calculated WBC count of $5500 / \mathrm{mm}^{3}$ was lower than previously reported for Thailand (HATHIRAT et al., 1976), possibly because WBC were lost during dehaemoglobinization (DOWLING \& SHUTE, 1966).

Table 1. Number of individuals infected annually with Plasmodium falciparum or $P$. vivax

\begin{tabular}{ccrrr}
\hline & & \multicolumn{2}{c}{ Individuals infected } & Annual \\
$\boldsymbol{P}$. falciparum & P. vivax & year 1 & year 2 & mean $(\%)^{2}$ \\
\hline+ & + & 115 & 139 & 70.2 \\
+ & - & 54 & 42 & 26.5 \\
- & + & 3 & 2 & 1.4 \\
- & - & 4 & 3 & 1.9 \\
Totals & & 176 & 186 & $100 \cdot 0$ \\
\hline
\end{tabular}

Percentage of those patent for each species at least once per year; mixed infections counted individually.
Fever was reported more frequently in those $<10$ years old $(8 \cdot 1 \%)$ than in those older $(2 \cdot 7 \%)$, but in both groups it appeared to occur independently of malaria infection (Table 4). It was possible that low grade fever was so common that it was unnoticed (MACDONALD, 1926); the mean temperature of all children $<10$ years old in January and February 1985

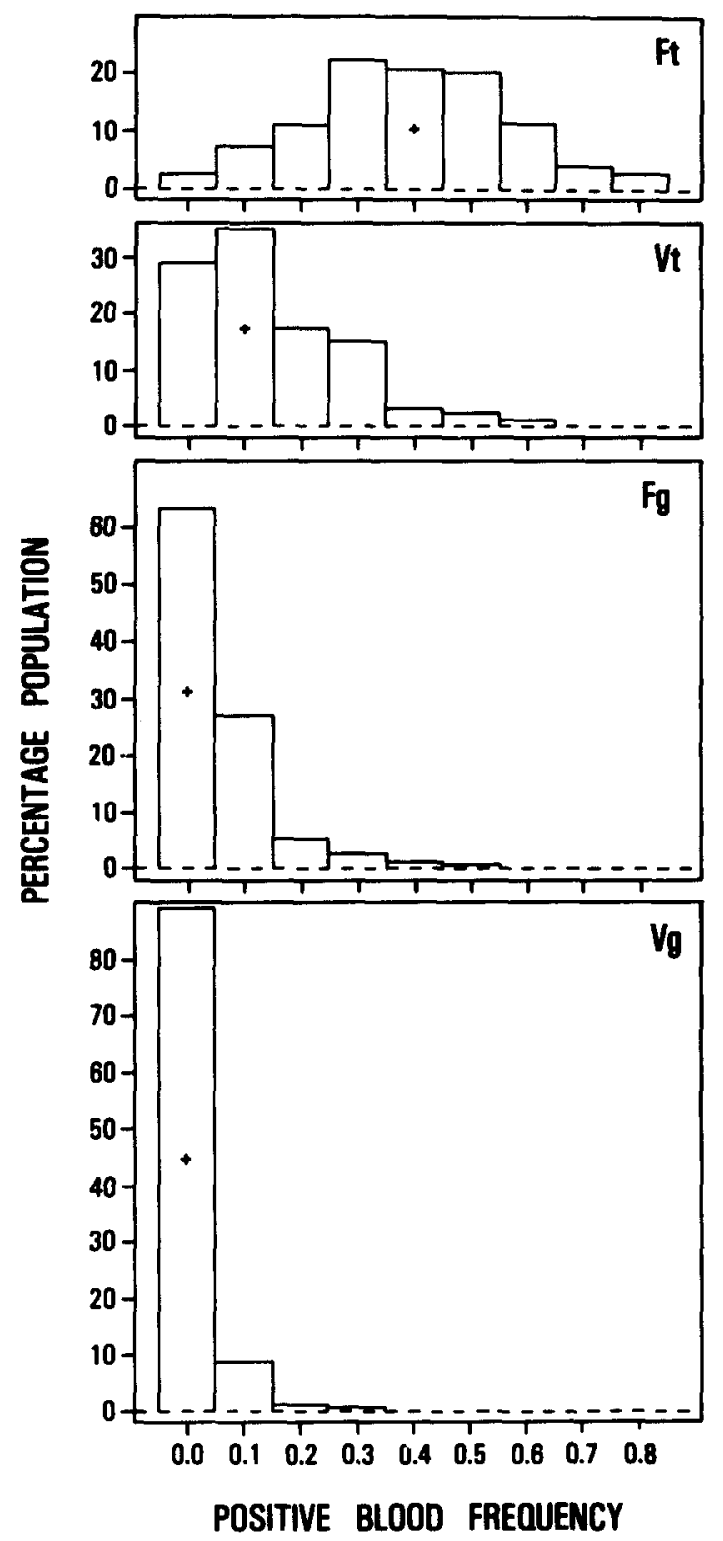

Fig. 1. Annual frequency distributions of malaria prevalence in a population at Ban Phluang, Thailand. Individual prevalences were calculated as the proportion of months in which blood was examined (8-12) and found to be positive: $\mathrm{Ft}=$ Plasmodium falciparum trophozoites; $\mathrm{Fg}=P$. falciparum gametocytes; $\mathrm{Vt}=P$. vivax trophozoites; $\mathrm{Vg}_{\mathrm{g}}=P$. vivax gametocytes. Distributions were calculated for each of the two years, then averaged; there was no evident difference between the years. Median frequencies are marked with plus signs $(+)$. 
Table 2. Observed and expected number of mixed and individual Plasmodium falciparum and $P$. vivax infections"

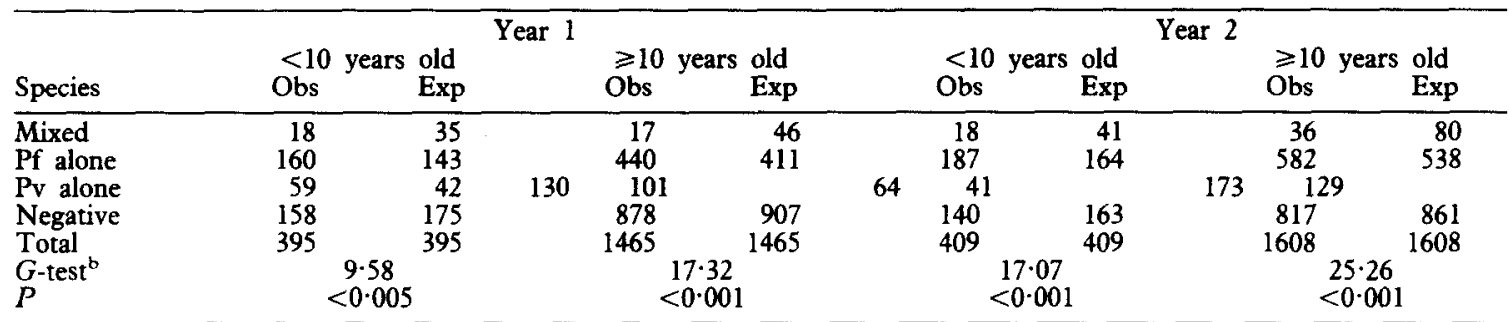

${ }^{a}$ Abbreviations: $\mathrm{Pf}=P$. falciparum; $\mathrm{Pv}=P$. vivax; Obs=observed; Exp=expected. Expected values were at least twice observed values for each of 24 months. Comparison of wet and dry seasons for combined ages not shown; Obs/Exp for June-October $=0 \cdot 47$, for November-May $=0 \cdot 44$.

bexpected values from $2 \times 2$ contingency tables, 1 degree of freedom. $G$-test is $\log$ likelihood ratio test (SoKAL \& ROHLF, 1981), 1 degree of freedom.

Table 3. Age distribution of malaria prevalence, 24 months

\begin{tabular}{lcccccc}
\hline & & & \multicolumn{2}{c}{ Cases/man-month } \\
Age (years) & No. & Man-months & Pft & Pfg & Pvt & Pvg \\
\hline$<1$ & 11 & 49 & 0.33 & 0.08 & $0 \cdot 12$ & 0.02 \\
$1-4$ & 16 & 372 & 0.51 & $0 \cdot 10$ & $0 \cdot 17$ & 0.03 \\
$5-9$ & 19 & 399 & 0.50 & 0.09 & $0 \cdot 24$ & 0.03 \\
$10-14$ & 24 & 435 & 0.33 & 0.06 & $0 \cdot 17$ & 0.02 \\
$15-19$ & 32 & 578 & 0.37 & 0.04 & $0 \cdot 12$ & 0.01 \\
$\geqslant 20$ & 110 & 2075 & 0.38 & 0.03 & 0.11 & 0.004 \\
\hline
\end{tabular}

${ }^{\mathrm{a}} \mathrm{Pft}=$ Plasmodium falciparum asexual forms; $\mathrm{Pfg}=P$. falciparum sexual forms; $\mathrm{Pvt}=P$. vivax asexual forms; $P v g=P$. vivax sexual forms.

was $37 \cdot 1^{\circ} \mathrm{C}$. The prevalence of enlarged spleens, which was generally low, appeared to increase from December to February and then fall (Table 5), a pattern similar to that of transmission (ROSENBERG $e t$ al., 1990a). Only 3 deaths occurred during the 2 years, all adult males and none attributable to malaria.

Ages and parasite densities of those receiving treatment for $P$. falciparum infection were the same in both years. Clearance rates were identical for both QT and MSP $\left(\chi^{2}, P>0.1\right)$ (Table 6$)$. The only significant difference found between the 2 treatments was that the mean age of those positive after treatment was lower for QT $(P<0.01)$. Since treatment was based on the less sensitive first screening, drug recipients had substantially higher parasite densities than those who were positive and not treated. Infections responding to either form of treatment had the same initial geometric mean densities as those that did not $\left(\chi^{2}\right.$, $P_{\mathrm{QT}}=0.68, P_{\mathrm{MSP}}=0.33$ ); initial densities of untreated infections which spontaneously remitted and those that did not were also the same. However, among those treated who did not clear the parasitaemia, a disproportionate number were children $<10$ years old $\left(\chi^{2}, P_{\mathrm{OT}}<0.001, P_{\mathrm{MSP}}=0.015\right)$. Both drugs lowered densities significantly even when they failed to clear the parasite; by contrast, densities in those who were not treated increased (2 sample ANOVA: $\left.P_{\mathrm{QT}}<0.001, P_{\mathrm{MSP}}<0.001\right)$.

\section{Discussion}

Typically, a child born at Ban Phluang and remaining there was infected with $P$. falciparum bcfore the age of 1 year and remained infected throughout life. He or she would usually be positive for $P$. falciparum for 6 months annually and, in most years, would have a patent $P$. vivax infection for 1 or 2 months as well. Immunity would not build up to levels sufficient to reduce either parasite prevalence or density until about the age of 10 years, after which both would decline markedly but never disappear. Despite repeated infection during a period of developing immune response, the child would seldom be seriously ill or display characteristic symptoms of malaria.

Universal infection during infancy followed by decline of density, symptoms, and prevalence in early childhood are characteristics of hyperendemic foci everywhere (WILSON et al., 1950; MOLINEAUX \& GRAMICCIA, 1980; CATTANI et al., 1986). In other attributes, however, malaria at Ban Phluang differed from that often described from Africa. The child spleen index was low (WHO, 1963) and, although acute malaria often kills children in Africa (BRUCECHWATT, 1952; MCGREGOR et al., 1970; GREENWOOD et al., 1987), it did not do so at Ban Phluang. Furthermore, national health statistics suggest malaria contributes little to the rural infant mortality anywhere in Thailand (KANCHANARAKSA, 1987).

The people of Ban Phluang probably receive better nutrition and medical care than do most residents of tropical Africa, but these factors alone do not sufficiently explain the low childhood mortality at Ban Phluang; malaria mortality was also low in a poor and remote hyperendemic Bangladeshi community (ROSENBERG \& MAHESWARY, 1982). The key difference between Asia and Africa may be the rate of incidence (MCGREGOR, 1965): a resident received about 15 sporozoite inoculations per year at Ban 


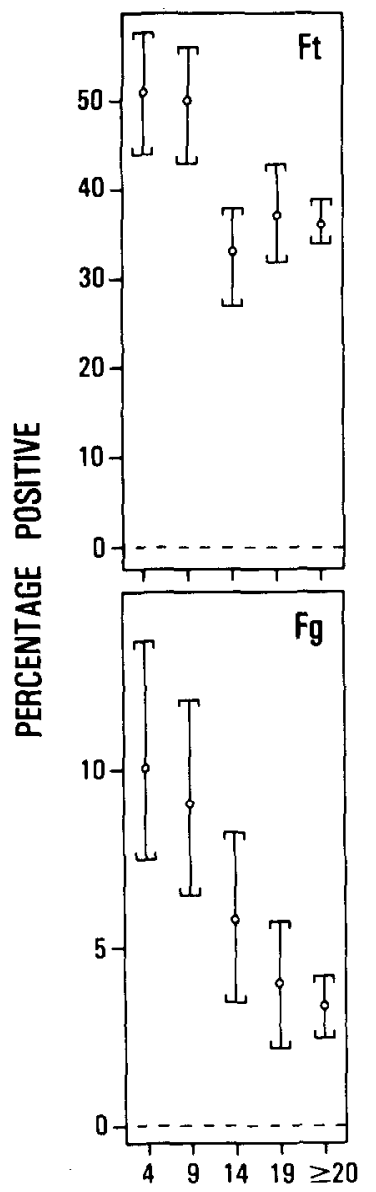

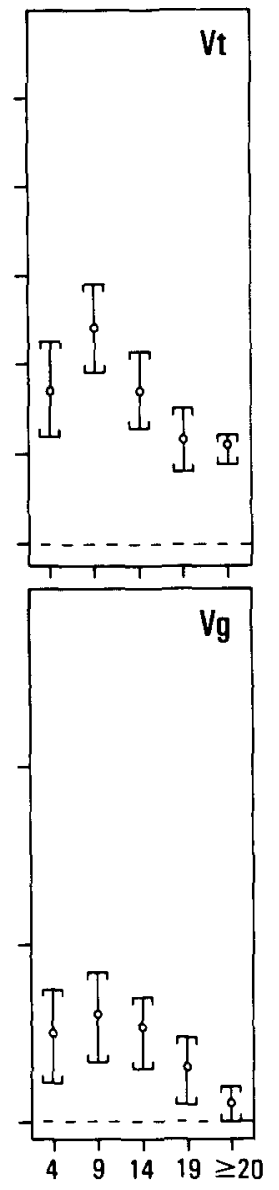

Fig. 2. Mean prevalence by age $(O)$ with $95 \%$ confidence intervals (vertical lines) based on pooled standard deviations; Ban Phluang, Thailand, June 1983-May 1985. Parasite numbers per 500 white blood cells analysed as logarithms; results shown as antilogs. As data were transformed, means may not be at centres of confidence intervals; data for infants are not shown as most were examined for fewer than 8 months/year. (Some of the data are also shown in Fig. 4.)

Phluang (RosENBERG et al., 1990a), only $10 \%$ of the number received at some African foci (MOLINEAUX \& GramiCCIA, 1980; PAYNE et al., 1976). Long-term, sterile immunity to malaria does not develop naturally and the clinical severity of the disease may be correlated with superinfection; partial chemosuppression of parasitaemia, for example, can reduce both fever and spleen prevalence without diminishing protective immunity (BJORKMAN et al., 1986). The minimum incidence necessary to maintain the semicommensalism characteristic of hyperendemicity is unknown, but apparently Ban Phluang is closer to the threshold, and consequently healthier, than many African foci.

Paradoxically, the re-checking microscopist examined a smaller volume of blood than did the zone microscopists but found nearly 3 times as many positive slides. The increased accuracy at re-check was mostly due to the greater experience of that technician, but prolonged examination $(10 \mathrm{~min}$ vs

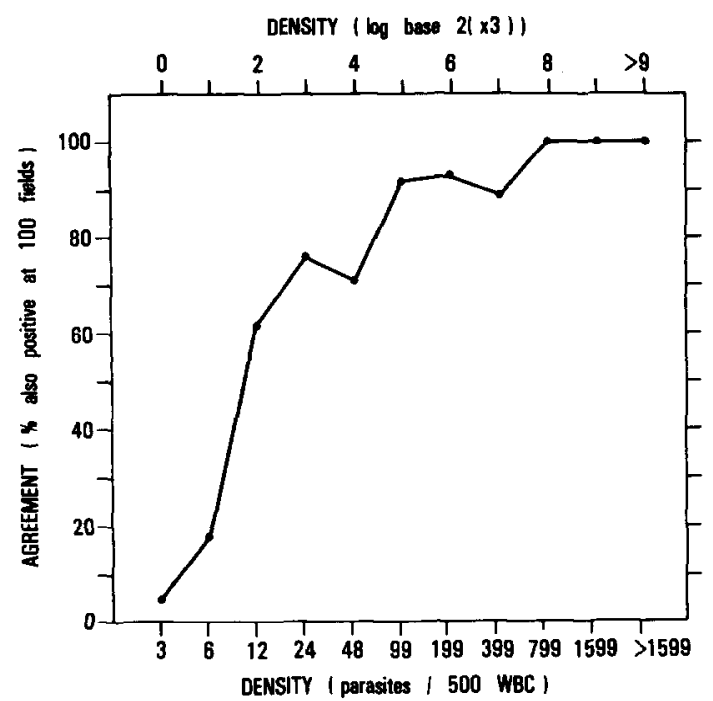

Fig. 3. Relationship between density and patency of Plasmodium falciparum trophozoites determined by two examination methods. (The proportions of 1471 thick films found positive, at given densities per 500 white blood cells (WBC), are compared with the number previously found positive, at any density, by microscopists routinely examining 100 fields for 3-5 min.)

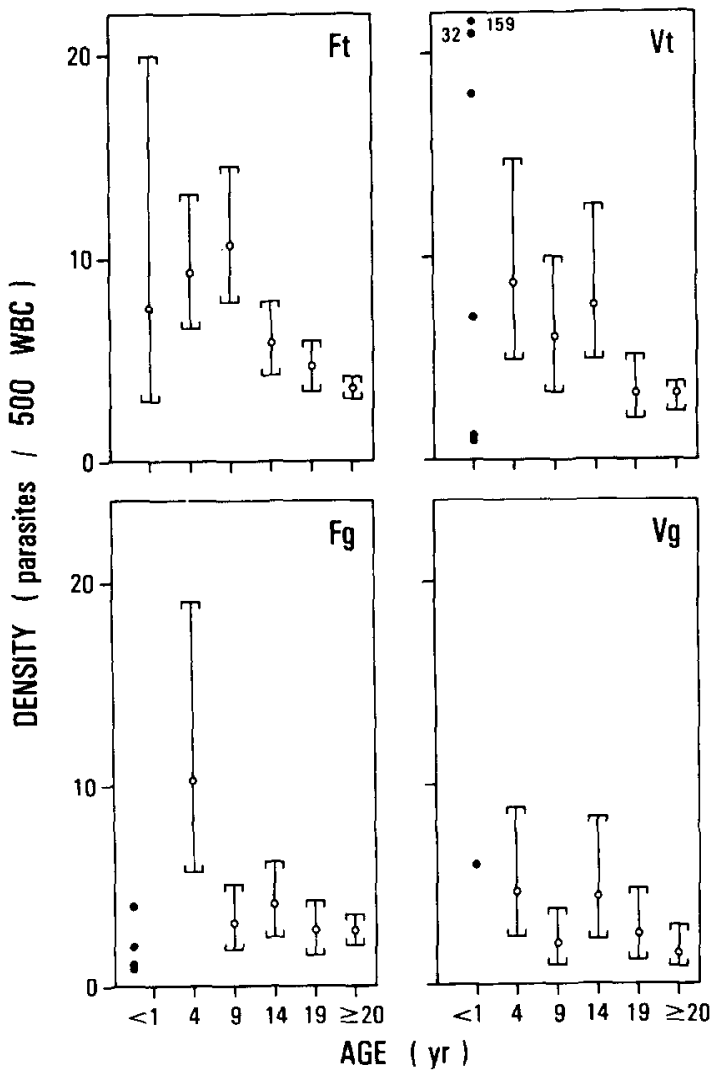

Fig. 4. Parasite density by age (means $(O)$ and $95 \%$ confidence intervals (vertical lines); based on pooled standard deviations. Details of analysis as for Fig. 2. Where infant data were too few to calculate meaningful confidence intervals, individual densities (O) are plotted.) 


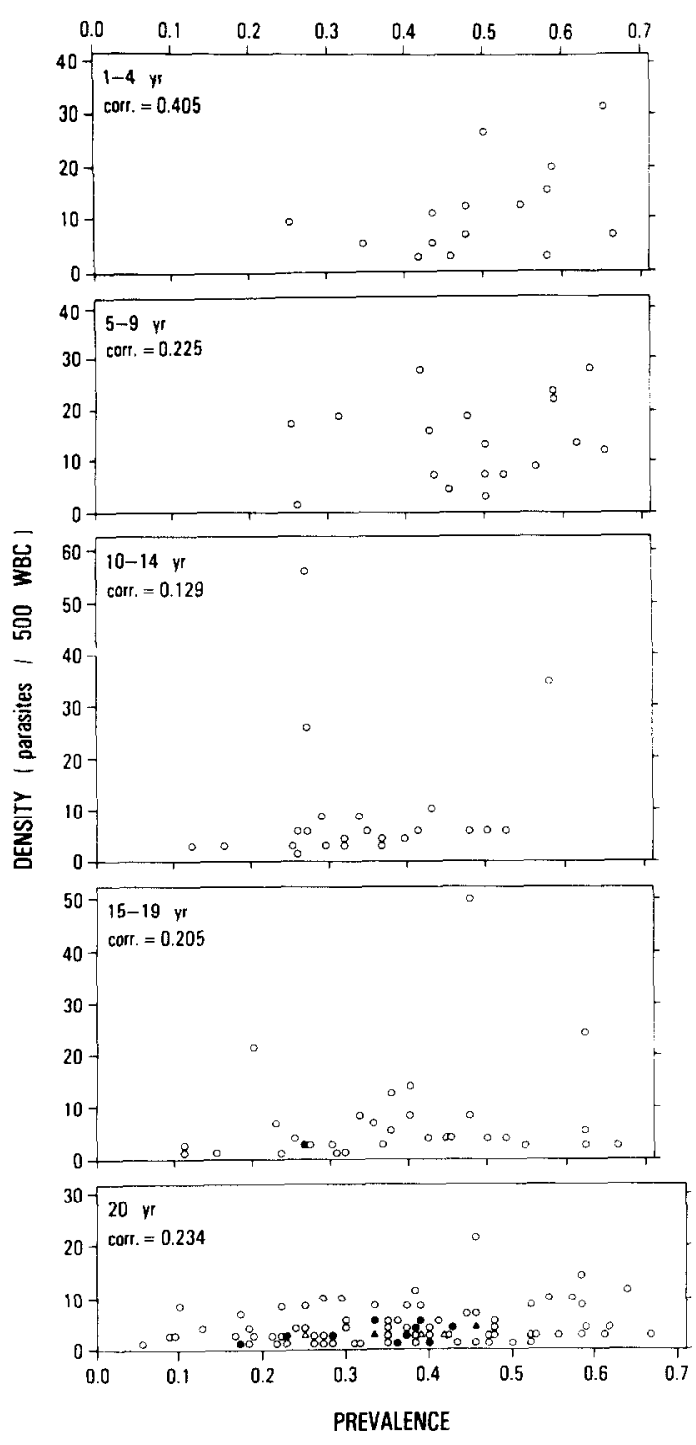

Fig. 5. Individual correlations, by age, between parasite density per 500 white blood cells and annual prevalence of Plasmodium falciparum trophozoites. (Each point represents the mean of two years' data; densities were calculated from positive values only; 2 or more coincident values are indicated thus: $\triangle=2, \Theta=3, \Delta=4$.)

Table 4. Fever history as indicator of concurrent Plasmodium falciparum infection

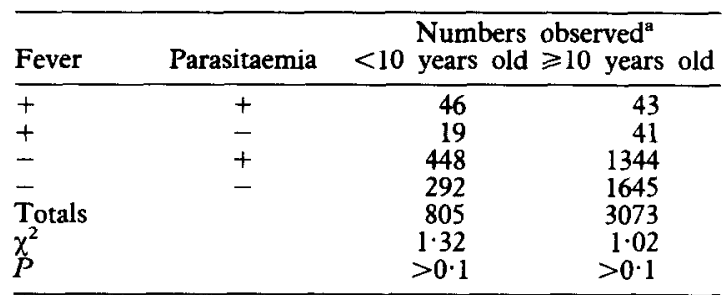

Totals of monthly individual paired blood examinations and histories. $\chi^{2}$ calculated for $2 \times 2$ contingency, 1 degree of freedom.
$3 \mathrm{~min}$ ) and higher magnification (1000x vs $700 \times)$ may also have been significant factors. The zone microscopists were efficient at discovering all potentially dangerous parasitaemias, but the accuracy of special surveys aimed at estimating the number of semi-immune persons might be improved if slides were examined longer and at higher magnification.

In general, densiries and prevalences declined together as children grew older. We speculated that, since age cohorts with the lowest prevalence had the lowest densities, then individuals with the lowest prevalences would also have the lowest densities. Analysis did not strongly support this hypothesis (except possibly in those 1-4 years old) and, as can be seen in Fig. 5, age restricted the range of densities more than individual prevalences, which remained widely scattered. These patterns suggest that immunity to merozoites was a more important regulatory mechanism than was immunity to sporozoites, which would have been expected to reduce prevalence disproportionally to density (MOLINEAUX \& GRAMICIA, 1980). The imperfection of acquired immunity was also made evident in this and other (MILLER, 1958; BRUCE-CHWATT, 1963; SEGAL et al., 1974) longitudinal studies by the universality of adult infections.

The number of mixed infections was much lower than expected. MOLINEAUX et al. (1980) have argued that this results from supression of one species by another. Indeed, about one-third of Thai patients successfully treated in a non-transmission area for apparently uncomplicated $P$. falciparum malaria subsequently developed patent $P$. vivax infection (LOOAREESUWAN et al., 1987). Notably, though, when mixed infections were seen at Ban Phluang, $P$. falciparum densities were higher than in single infections, a relationship described from Africa only in situations where mixed infections were more numerous than expected (MOLINEAUX et al., 1980). These observations imply that those residents of Ban Phluang with little immunity to either species displayed most of the mixed infections, as young children did, but that once an immune response to $P$. falciparum developed it suppressed $P$. vivax schizogony, causing a drop in the apparent, but not necessarily the real, rate of mixed infections.

The simplest explanation for our observation that MSP-which is administered in a single dose and is also prophylactic (CLYDE et al., 1976)-cured no more cases than did QT is that much of the drug delivered was not swallowed, probably because virtually no one felt ill. Those who received either drug and who were still parasitaemic the next month tended to have lower than expected densities, suggesting that many people partially complied. It also suggests that one or two days of quinine alone (SHARMA et al., 1985) was as efficacious as an incomplete dose of MSP in semiimmunes, who had lower densities than most drug trial participants. Since normally only the ill receive treatment, our finding will be of litule practical significance except in mass drug distributions.

Recently, much attention in Thailand has been given to malaria in transient persons who, because they are non-immune, display symptoms that swell the figures for annual parasite incidence (API). From 1980 to 1984, for instance, API rose steeply and then began to fall, describing a curve that appeared to be 
Table 5. Spleen rates among children and adults, 1984-1985

\begin{tabular}{lccccc}
\hline & Nov. & Dec. & Feb. & Jun. & Totals \\
\hline$<15$ years old & 18 & 50 & 37 & 55 & 160 \\
Sample size & 22 & 22 & 38 & 15 & 23 \\
Positive (\%) & & & & & \\
$\geqslant 15$ years old & 2 & - & 47 & 119 & 168 \\
Sample size & 0 & - & 11 & 6 & 7 \\
Positive (\%) & & & & & \\
\hline
\end{tabular}

a9. $2 \%$ of palpable spleens in children $<15$ years old and all those in children $\geqslant 15$ years old were Hackett's grade 1 .

Table 6. Relative efficiency of quinine+tetracycline and mefloquine+sulfadoxine+pyrimethamine for clearing Plasmodium falciparum trophozoites in a semi-immune population

\begin{tabular}{|c|c|c|c|c|c|c|}
\hline Treatment $^{\mathrm{a}}$ & Follow-up ${ }^{b}$ & Sample & Cure & Age & & $i^{\text {d }}$ \\
\hline (Day 0) & (Day 30) & size & rate $^{c}$ & (years) & Day 0 & Day 30 \\
\hline 1983 & & & & & & \\
\hline QT & + & 55 & - & 16.9 & 35.9 & $17 \cdot 4$ \\
\hline QT & - & 77 & $55.6 \%$ & 24.9 & $22 \cdot 4$ & 0 \\
\hline None & + & 81 & - & $23 \cdot 6$ & $4 \cdot 3$ & $7 \cdot 0$ \\
\hline None & - & 149 & $64 \cdot 8 \%$ & $29 \cdot 1$ & $3 \cdot 7$ & 0 \\
\hline 1984 & & & & & & \\
\hline MSP & + & 45 & - & $21 \cdot 1$ & $18 \cdot 2$ & 6.4 \\
\hline MSP & - & 50 & $52 \cdot 6 \%$ & $25 \cdot 0$ & $22 \cdot 4$ & 0 \\
\hline None & + & 151 & - & $26 \cdot 1$ & 3.6 & $5 \cdot 9$ \\
\hline None & - & 210 & $58 \cdot 2 \%$ & $29 \cdot 3$ & $4 \cdot 2$ & 0 \\
\hline
\end{tabular}

${ }^{\mathrm{a} T}=$ quinine + tetracycline; $\mathrm{MSP}=$ mefloquine + sulfadoxine + pyrimethamine.

bollow-up: +=patent $30 \mathrm{~d}$ later; $-=$ negative $30 \mathrm{~d}$ later.

'Cure rate: percentage of each treatment group negative after $30 \mathrm{~d}$.

dDensity: geometric mean of trophozoites $/ 500$ white blood cells.

correlated with a large ingress of gem miners, soldiers, and refugees to the eastern provinces and their subsequent departure as the mines were depleted, the border stabilized, and control measures established. Malaria among these people, and among farmers from non-endemic villages who sleep or work in the forest at night, accounts for almost all the reported malaria in Thailand (PINICHPONGSE, 1986), but probably only a small percentage of the real national prevalence. The dependence on PCD statistics helps to foster the illusion that hyperendemic malaria does not exist in Thailand (WHO, 1988). Not only do cryptic foci occur elsewhere in the southeastern (THIMASARN \& BRANDLING-BENNETT, 1982) and southern provinces (R. G. Andre and R. Rosenberg, unpublished observations), but the favourable vector habitat of rubber and fruit tree plantations is increasing (ROSENBERG et al., 1989a). The part these foci play in the development of drug resistance, infection of migrant workers and visitors, and maintenance of forest transmission is largely unexplored.

\footnotetext{
Acknowledgements

We thank Surin Pinichpongse (Director), Sunchai Ketrangsee, Chusak Prasittisuk, and Krongthong Thimasarn of the Malaria Division, Ministry of Public Health, Bangkok for their cooperation and M. Benenson and F. Sodetz, Directors of the US Army Medical Component, for support. Nongnuj Maneechai, Lek Somchit, Sanit Nakngen, Ruan Thaopha, Somporn Chanaimongkol, Inkam Inlao, Chum-
}

nong Noigamol, Vichit Phunkitchar and Suwattana Vongpradit of the Entomology Department, Armed Forces Institute of Medical Sciences, Bangkok, provided expert technical assistance. E. Kaplan and $P$. Rummel devised computer programs essential for analysing the data. D. F. Clyde, M. T. Gillies, J. D. Haynes, I. A. McGregor, J. Meuwissen, L. Molineaux and McW. Warren kindly reviewed drafts of this and the 2 related reports; they may not agree with all our conclusions.

\section{References}

Bjorkman, A., Brohult, J., Pehrson, P. O., Willcox, M., Rombo, L., Hedman, P., Kollie, E., Alestig, K., Hanson, A. \& Bengtisson, E. (1968). Monthly antimalarial chemotherapy to children in a holoendemic area of Liberia. Annals of Tropical Medicine and Parasitology, 80, 155-167.

Black, R. H. (1986). Manual of Epidemiology and Epidemiological Services in Malaria Programmes. Geneva: World Health Organization (ME/68.5).

Bruce-Chwatt, L. J. (1952). Malaria in African infants and children in southern Nigeria. Annals of Tropical Medicine and Parasitology, 46, 173-200.

Bruce-Chwatt, L. J., editor (1961). Manual for Processing and Examination of Blood Slides in Malaria Eradication Programmes. Geneva: World Health Organization.

Bruce-Chwatt, L. J. (1963). A longitudinal survey of natural malaria infection in a group of West African adults. West African Medical Journal, 12, 141-173 \& 199-212.

Cattani, J. A., Tulloch, J. L., Vrbova, H., Jolley, D., Gibson, F. D., Moir, J. S., Heywood, P. F., Alpers, M. P., Stevenson, A. \& Clancy, R. (1986). The epidemiology of malaria in a population surrounding Madang, 
Papua New Guinea. American Foumal of Tropical Medicine and Hygiene, 35, 3-15.

Clyde, D. F. (1987). Variation in response of malaria parasites to drugs in Asia and Oceania. La Medicina Tropicale rella Cooperazione allo Sviluppo, 3, 3-22.

Clyde, D. F., McCarthy, V. C., Miller, R. M. \& Hornick, R. B. (1976). Suppression activity of mefloquine in sporozoite-induced human malaria. Antimicrobial Agents and Chemotherapy, 9, 384-386.

Dowling, M. A. C. \& Shute, G. T. (1966). A comparative study of thick and thin blood films in the diagnosis of scanty malaria parasitaemia. Bulletin of the World Health Organization, 34, 249-267.

Earle, W. C. \& Perez, M. (1932). Enumeration of parasites in the blood of malarial patients. Foumal of Laboratory and Clinical Medicine, 17, 1124-1133.

Greenwood, B. M., Bradley, A. K., Greenwood, A. M., Byass, P., Jammeh, K., Marsh, K., Tulloch, S., Oldfield, F. S. J. \& Hayes, R. (1987). Mortality and morbidity from malaria among children in a rural area of The Gambia, West Africa. Transactions of the Royal Society of Tropical Medicine and Hygiene, 81, 478-486.

Hackett, L. W. (1944). Spleen measurement in malaria. Foumal of the National Malaria Society, 3, 121-133.

Hathirat, P., Israngkura Na Ayuthya, P., Sasanakul, W., Bintadish, P. \& Boonvanich, P. (1976). Hematological findings in normal Thai children. Fournal of the Medical Association of Thailand, 59, 54-57.

Kanchanaraksa, S., editor (1987). Review of the Health Situation in Thailand. Bangkok: Rockefeller Foundation.

Kondrashin, A. V. \& Orlov, V. S. (1985). Malaria in southern Asia. 4. Migration of population in India and its role in the epidemiology of malaria. Meditsinskaya Parazitologiya i Parazitamye Bolezni, No. 2, 46-51. [In Russian, English abstract.]

Looareesuwan, S., White, N. J., Chittamas, S., Bunnag, D. \& Harinasuta, T. (1987). High rate of Plasmodium vivax relapse following treatment of falciparum malaria in Thailand. Lancet, i, 1052-1055.

Macdonald, G. (1926). Malaria in children in Freetown, Sierra Leone. Annals of Tropical Medicine and Parasitology, 20, 239-261.

Macdonald, G. (1957). The Epidemiology and Control of Malaria. London: Oxford University Press.

Malaria Division (1982). General Information on the Antimalaria Programme in Thailand. Bangkok: Ministry of Public Health.

McGregor, I. A. (1965). Consideration of some aspects of human malaria. Transactions of the Royal Society of Tropical Medicine and Hygiene, 59, 145-152.

McGregor, I. A., Rahman, A. K., Thomson, A. M. Billewicz, W. Z. \& Thompson, B. (1970). The health of young children in a West African (Gambian) village. Transactions of the Royal Society of Tropical Medicine and Hygiene, 64, 48-77.

Meek, S. R., Doberstyn, E. B., Gauzere, B. A., Thanapanich, C., Norlander, E. \& Phuphaisan, S. (1986). Treatment of falciparum malaria with quinine and tetracycline or combined mefloquine/sulfadoxine/ pyrimethamine on the Thai-Kampuchean border. Amer- ican Journal of Tropical Medicine and Hygiene, 35, 246-250.

Miller, M. J. (1958). Observation on the natural history of malaria in the semi-resistant West African. Transactions of the Royal Society of Tropical Medicine and Hygiene, 52, 152-168.

Molineaux, L. \& Gramiccia, G. (1980). The Garki Project. Geneva: World Health Organization.

Molineaux, L., Storey, J., Cohen, J. E. \& Thomas, A. (1980). A longitudinal study of human malaria in the west African savanna in the absence of control measures: relationships between different Plasmodium species, in particular $P$. falciparum and $P$. malariae. American Foumal of Tropical Medicine and Hygiene, 29, 725-737.

Payne, D., Grab, B., Fontaine, R. E. \& Hempel, J. H. G. (1976). Impact of control measures on malaria transmission and general mortality. Bulletin of the World Health Organization, 54, 369-377.

Pinichpongse, S. (1986). Malaria control in Thailand. In: Second Conference on Malaria Research, Thailand. Bangkok: Ministry of Public Health, pp. 24-33.

Rosenberg, R. \& Maheswary, N. P. (1982). Forest malaria in Bangladesh. I. Parasitology. American foumal of Tropical Medicine and Hygiene, 31, 175-182.

Rosenberg, R., Andre, R. G. \& Somchit, L. (1990a). Highly efficient dry season transmission of malaria in Thailand. Transactions of the Royal Society of Tropical Medicine and Hygiene, 84, 22-28.

Rosenberg, R., Andre, R. G. \& Ketrangsee, S. (1990b) Seasonal fluctuation of Plasmodium falciparum gametocy. taemia. Transactions of the Royal Society of Tropical Medicine and Hygiene, 84, 29-23.

Segal, H. E., Wilkinson, R. N., Thiemanun, W., Gresso, W. E. \& Gould, D. J. (1974). Longitudinal malaria studies in rural north-east Thailand: demographic and temporal variables of infection. Bulletin of the World Health Organization, 50, 505-512.

Sharma, G. K., Barkakaty, B. N., Sharma, P., Bhuyan, M. K. \& Kalita, P. C. (1985). Efficacy of single dose quinine as presumptive treatment in $P$. falciparum malaria. Indian Fournal of Malariology, 22, 29-34.

Sokal, R. R. \& Rohlf, F. J. (1981). Biometry. San Francisco: Freeman.

Thimasarn, K. \& Brandling-Bennett, A. D. (1982). Prevalence of Asymptomatic Malaria in Chantaburi and Trad Provinces ( 7 une-November, 1981). Bangkok: Malaria Division, Ministry of Public Health (mimeographed document).

WHO (1963). Terminology of Malaria and Malaria Eradication. Geneva: World Health Organization.

WHO (1988). Malaria Diagnosis. Geneva: World Health Organization, mimeographed document no. WHO/ MAL/88.1045.

Wilson, D. B., Garnham, P. C. C. \& Swellengrebel, N. H. (1950). A review of hyperendemic malaria. Tropical Diseases Bulletin, 47, 677-698.

Received 15 December 1988; accepted for publication 30 March 1989 